\title{
SOCIO-DEMOGRAPHIC DIFFERENCES IN THE Perceptions of LEARNing MANAgEMENT SYSTEM (LMS) DESIGN
}

\author{
Yee Mei Lim ${ }^{1}$, Aladdin Ayesh ${ }^{2}$ and Keh Niang Chee ${ }^{3}$ \\ ${ }^{1}$ Faculty of Applied Sciences and Computing, Tunku Abdul Rahman University College \\ ${ }^{2}$ Faculty of Technology, De Montfort University \\ ${ }^{3}$ Faculty of Applied Sciences and Computing, Tunku Abdul Rahman University College
}

\begin{abstract}
Learner centred design (LCD) focuses on creating an e-learning system that can fulfil individual needs through personalization, nevertheless there are still many technical challenges. Besides, losing balanced focus on both of the learners and the instructors does not help to create a successful e-learning system. User-centred design helps to improve the usability of a system as it integrates requirements and user interface designs based on users' needs. The findings of this research prove that even the users are provided with the same LMS, not everyone has the same perceptions or tolerance levels of the seven design factors that may cause frustrations to the users, and not everyone has the same satisfaction level of navigation experience and interface design. It is important for the LMS developers to understand that the variations between roles, genders, experiences and ages exist and should not be ignored when designing the system.
\end{abstract}

\section{KEYWORDS}

Learning Management System, Socio-demographics Differences, User-centred Design, User Interface Design, User Satisfactions

\section{INTRODUCTION}

Many universities have employed e-learning into their educational programs, it is important to design a usable system for these institutes to sustain their e-learning environment. Having a strategic planning and implementation, and the right technological, governmental and institutional supports is vital for the successful implementation of e-learning system [1-4]. Besides, a research by [5] proved that some other factors are also deemed important to the e-learning users, which include program content, Web page accessibility, learners' participation and involvement, website security and support, interactive environment, instructor competency, and presentation and design. Their research discovered that none of their participants consider program content, Web page accessibility, participation and involvement, and presentation and design are not important. Therefore we agree that a successful e-learning system must at least to be designed with good and adequate program content, which is presented well and can be accessed easily, and to allow high user participation and involvement in the virtual learning environment. However, as argued by [6], different learners may have different learning needs, and different users may have different requirements on how the program content should be displayed, therefore user-centered design plays an important role in determining the success of e-learning.

DOI : 10.5121/ijsea.2013.4502 
User-centred design, which is the process of integrating user requirements, user interface validation and testing into standard software design methods, views knowledge about users and their involvement in the design process as a central concern [7]. It is important to note that for all systems, users are the one who will be committed to using the system and living with the impact on system design in the e-learning environment, but not the system providers. However, there are many tool vendors provide solutions using a generic "one size fits all" tool-focused approach. By focusing only on tool design, rather than the overall system usability, this approach often ignores what it takes to make a successful e-learning system. A technology should be designed based on how each individual should use the system within the context of their roles and responsibilities. It is evident that users with different roles will have different learning needs [8]. Therefore the design and implementation of technological models for virtual learning should satisfy individual user differences by respecting user strategies, self-regulation and learning management [9].

To ensure users' needs are satisfied, usability testing fits in as one part of the user-centred design process. In a usability test, representative users try the functionality of the system and to identify areas where users struggle with the system, to make recommendations for improvement. However, to conduct a valid test, the usability practitioners should consider the heterogeneity of the representative users, as heterogeneity makes difference to standardize the quality of design.

\section{USER-CENTRED DESIGN IN E-LEARNING SYSTEMS}

The increasing heterogeneity of the users' population, the diversification of learners' learning needs and tasks, and the decreasing tolerance of users' frustration motivate the application of the user-centred model in e-learning design [10]. User-centred design is one of the significant criteria to improve the usability of a system as it integrates requirements and user interface designs based on users' needs. By focusing on the end users, we ensure they are satisfied with a more efficient and user-friendly navigation experience, hence their loyalty and return visits will increase as the system supports rather than frustrates them. This will indirectly promote users' active participation and involvement in using the system to help the learners learning the content effectively.

[11] argued that a learner-centred design should be adopted over user-centred design when designing an e-learning platform. Learner-centred design (LCD) requires the design to be done by creating a characterization for each learner profile based on their personality, learning preferences, learning behaviours or styles, motivation background knowledge, experience with the course content and the system, location and culture, inter alia [12-17]. The theory of LCD was raised by [18], which they differentiate between user-centred model (UCM) and learnercentred model (LCM). They claim that UCM focuses on tasks, tools and interfaces (TTI), whilst LCM focuses on tools, interfaces, learner's needs and task (TILT). The TILT model suggests some scaffolding strategies for the special needs of the learner. For instance coaching is needed to help students acquire knowledge and practices of a task domain, tools must be adaptable to support learner growing expertise, and interface must allow learners to communicate and express themselves by the use of different media and mode.

Learner-centred design in e-learning can be implemented through personalization or adaptive systems. In this approach, an intelligent system is built to personalize and adapt e-learning content, pedagogical models, and interactions between participants in the virtual learning environment to meet the individual needs and preferences of users when they arise. The learner model is an essential component in adaptive e-learning systems since it is used to modify the interaction between system and learners to suit the needs of individual learner [19]. 
Semantic analysis and intelligent agents appear to be the main technologies to implement personalization for e-learning systems [20-23]. Adaptive system makes the content changes automatically to fulfil the requirements of the individual learner. Although the emergence of personalization provides better content selection based on individual needs to increase the usage of the e-learning materials [24], nevertheless the development of this type of systems can be technically challenging and expensive.

Furthermore, LCD places instructors (teachers, lecturers or tutors) on the secondary position. However it is important to note that instructors are also the main users who play important role in designing the course content and the information layout display. [25] proved that instructor's attitudes toward e-learning have a significant effect on learners' satisfaction. In other words, instructor should handle e-learning activities and respond to students' problems promptly to improve learning satisfaction. Therefore it is important to design a system to encourage the instructors to use the e-learning system as a tool to promote learning. If the interfaces are designed to be a hindrance to the use by all users, then the system is considered unsuccessful as it does not help to increase the participation and involvement of the users in the virtual learning environment.

To ensure the success of the e-learning system, it is critical to create a system that supports rather than frustrates users. According to [26], the common step to start designing a successful elearning system is to design usable user interfaces. Designing a usable interface is very important because it has a negative impact on user performance if it is not done correctly [27]. User interface design affects users' task completion and navigation experience [28]. However, by using the "one size fits all" approach to provide a general design for all users may not be effective, as different users would have different preferences, levels of tolerance and perceptions of the interface design and usability. When the implementation of personalization is not a feasible solution for the institution, it is important to at least consider users from different sociodemographic background when designing the interfaces.

Many studies have proven that culture differences are significant in designing the e-learning system [29-31], but there are limited research done to study the significance of gender, age, experience and role differences on the design of e-learning system. According to a study by [32], it was proven that women's perceptions are different from male co-workers when using e-mail, although these gender differences do not affect actual use. [33] proved that search performance slows with age when finding special computer icon. There is also individual variability in search performance within all age groups. [34] stated that novice users suffer even more frustration than experienced user, as they do not have a lot of computer experience, and therefore can easily get frustrated. Besides, it is also evident that users with different roles will have different learning needs [8]. In sum, it is necessary to study different user needs according to different sociodemographic, such as gender, age, experience and user role, to understand their perceptions and tolerance levels of the system usability and design.

\section{The User Interface (UI) Design Factors that Cause FRUSTRATIONS}

According to ISO 9241-11, usability is defined as "the extent to which a product can be used by specified users to achieve specified goals with effectiveness, efficiency and satisfaction in a specified context of use [35]. As cited by [26], [36] integrated ISO 9241 with the formative evaluation, and defined effectiveness as how much the learner interprets correctly the instructional interface functions, efficiency as the learner's experience of a minimal frustration in using instructional interface elements, and satisfaction as how much learners feel comfortable in 
the overall environment. It is important to note that satisfaction is correlated to emotion, and outcome satisfaction is positively related to user's enjoyment of the overall experience [37], [38]. In other words, if the overall experience using the system is positive, then the user's emotion towards the system is also positive (satisfaction).

A study by [34] shows that between a third and a half of the time on computer is spent on frustrating experiences. Amongst all the reasons, Web navigation appears to be the largest cause of users' frustrations. To investigate the user interface design factors that can cause user frustration on Web navigation, twelve literatures were examined and those factors that are related to user interface design were summarized [34], [39-49]. Finally seven factors that are considered would affect the user navigation experience in the e-learning environment were selected. The seven design factors are as follows:

1. Confusing features -- For example if two different features are given similar names, they can cause confusion.

2. A page that is packed with too many features -- A page that is full of buttons, hyperlinks or information can cause distraction and difficulty in looking for the desired feature.

3. Inconsistent layout design -- Inconsistent layout design will delay user's navigation. For example, a "save" button is placed on the left on first page, but it is placed on the right on the subsequent page. The user may need to spend extra time to look for the same button.

4. Unrecognisable hyperlinks/buttons -- User will take longer time to recognize a hyperlink that does not appear like a link, or a menu button that does not look like a button.

5. Current location is not informed -- User could be lost in the space after browsing a few pages when there is no hint on his/her current location and it can be even more frustrating if he/she does not know how to go back to the main page.

6. No explanation on "unpopular" features/activities -- We cannot expect users to know every single feature on the website. When there is no explanation/tooltip given to describe the features, the users may need to try one by one until they achieve what they are looking for.

7. Ambiguous terms used for the features -- The terms used to describe the features are confusing, or too technical and difficult to understand. This can be worse when no explanation is given.

\section{RESEARCH OBJECTIVES AND RESEARCH QUESTIONS}

The objectives of this research are to:

1. examine the correlations of the seven factors (as discussed in Section 3) with navigation experience satisfaction and user interface (UI) design satisfaction.

2. examine the effects of the socio-demographic background on the seven factors, navigation experience satisfaction and UI satisfaction.

To be able to achieve the objectives above, there are three research questions we would like to ponder:

1. Are there any correlations between the seven factors, navigation satisfaction and UI satisfaction?

2. Would e-learning users with different socio-demographic, i.e. user roles, genders, ages and experiences with the e-learning system perceive and tolerate the seven factors differently?

3. With the "one size fits all" design approach, do users with different socio-demographic, i.e. roles, genders, ages, and experiences perceive their satisfaction of the navigation and user interface design differently? 
International Journal of Software Engineering \& Applications (IJSEA), Vol.4, No.5, September 2013

\section{RESEARCH METHODOLOGY}

\subsection{Development of the Questionnaire}

The respondents who have experience with the e-learning system are required to answer three different sections regarding (1) their demographic background that includes role, experience with the LMS, gender and age (2) their acceptance levels of the seven design factors and (3) their navigation experience and user interface design satisfaction with the e-learning system.

The questions in Section 2 and Section 3 are set as follows:

Section 2

2.1. Did you find any features or links that were confusing when you were new to Blackboard? (CF)

2.2. All the pages of Blackboard are loaded with too many buttons and links. Do you agree? (TM)

2.3. The layout design and choice of colours are consistent. Do you agree? (CL)

2.4. The textual hyperlinks are visible and easy to recognize. Do you agree? (VH)

2.5. The Blackboard always keeps users informed about their current navigations/locations. Do you agree? (IL)

2.6. The Blackboard always displays proper explanations of the actions and validations to be carried out. Do you agree? (FE)

2.7. The Blackboard offers good use of terms or images to help the user to understand what the purpose of a feature is. Do you agree? (CT)

Section 3

3.1. Overall, how satisfied are you with the navigation design? (NV)

3.2. Overall, how satisfied are you with the user interface design? (UI)

Most of the questions above are provided with examples and explanations to ensure participants' understanding of the questions. A pre-test pilot of the questionnaire was done to help finalizing the questions and the format before the online survey is open for the participants. Except Item 2.1, which use nominal scale ( 1 for yes and 2 for no), all other questions are based on 5-point Likert scales ( 1 for strongly agree/very satisfied to 5 for strongly disagree/not satisfied at all). Item 2.1 to Item 3.2 are the nine dependent variables in this study.

\subsection{Hypotheses}

To answer the Research Question 1, we hypothesize that the correlations of the seven dependent variables as stated in Section 5.1 (Item 2.1 to Item 2.7), NV (Item 3.1) and UI (Item 3.2) exist.

H1: The correlations of the seven design factors, navigation experience satisfaction and UI design satisfaction are significant.

To answer the Research Question 2 and 3, and to examine the interactions between role, experience, gender, and age that affect the nine dependent variables, we set the following seven hypotheses ( $\mathrm{H} 2$ to $\mathrm{H} 8$ ). Hypotheses $\mathrm{H} 2$ to $\mathrm{H} 5$ are tested as exploratory study to examine the main effects of the independent variables, with the assumption that the users are homogeneous.

H2: Different roles (instructor or student) will perceive the nine dependent variables differently. H3: Different genders (male or female) will perceive the nine dependent variables differently. 
International Journal of Software Engineering \& Applications (IJSEA), Vol.4, No.5, September 2013

H4: Different users from different age groups will perceive the nine dependent variables differently.

H5: Different users with different length of experience will perceive the nine dependent variables differently.

To improve the precision with which comparisons among the factors of interest are made, it is important to test the effects of two or more factors. In our research, students and instructors have different age groups. Besides, the amounts of features they can view are different according to their respective role. Therefore we separated the analysis of age differences according to role. The overall interaction effects for three factors, namely role, gender and experience, are tested for all users. For students and instructors, we studied the interaction effects for gender, experience and age in separate analyses:

H6: At least two factors of role, gender and experience of all users interact with each other to provide significant effects to the nine dependent variables.

H7: At least two factors of gender, experience and age of the instructors interact with each other to provide significant effects to the nine dependent variables.

H8: At least two factors of gender, experience and age of the students interact with each other to provide significant effects to the nine dependent variables.

\subsection{The Survey}

The data for this study are gathered by means of an online survey questionnaire, which was made available for a month. We invited only those students and instructors who have experience with the e-learning system to participate in the survey. The research is taken place at Tunku Abdul Rahman College ${ }^{1}$, Malaysia. The institution set up five branches all over Malaysia, and has a population of more than 25 thousands students and 600 lecturers. The branches are located at four different states in west peninsular of Malaysia (Johor, Pahang, Penang, Perak) and one in east peninsular (Sabah). Hence, this provides us a very good sample to collect the opinions of the users from multiple states in the country.

\subsection{The E-learning Platform}

The institution employs the Blackboard Learning System (under Blackboard Academic Suite) to provide e-learning environment via the Internet. To enable blended-learning, the system allows the instructors to create and manage course matter, communicate with students, and evaluate student performance.

[50] argued that one of the limitations associated with the Blackboard learning management system (LMS) is the software is harder to learn than expected. Besides being "inflexible", there is a "learning curve for the system that precludes full and timely utility". Although the Blackboard system allows the administrators to determine how the courseware and specific class are structured. However the fixed structure designs are likely conflict with many instructors' goals. That could prevent course instructors and students to acquire an environment optimized for effective learning and teaching. In other words, it provides less control for the lower level users, such as instructors and students, over how they wish to structure their online experiences [51].

Based on the above, we consider Blackboard LMS is a good e-learning platform for us to examine the perceptions of different groups of e-learning users of the LMS according to different socio-demographic background, especially between instructors and students.

\footnotetext{
${ }^{1}$ The institution is known as Tunku Abdul Rahman University College since 2013.
} 
International Journal of Software Engineering \& Applications (IJSEA), Vol.4, No.5, September 2013

\subsection{Demographic Data}

Table 1. Distribution of Respondents

\begin{tabular}{|l|c|c|c|c|c|c|c|c|c|c|c|}
\hline \multirow{2}{*}{$\begin{array}{l}\text { Variable } \\
\text { S }\end{array}$} & \multicolumn{2}{|c|}{ Gender } & \multicolumn{3}{|c|}{ Experience (years) } & \multicolumn{6}{|c|}{ Age (years) } \\
\cline { 2 - 12 } & $\mathbf{M .}$ & $\mathbf{F}$ & $<\mathbf{1}$ & $\mathbf{1 - 2}$ & $\mathbf{3}$ & $\begin{array}{c}\mathbf{1 7 -} \\
\mathbf{2 0}\end{array}$ & $\begin{array}{c}\mathbf{2 1 -} \\
\mathbf{2 5}\end{array}$ & $\begin{array}{c}\mathbf{2 6 -} \\
\mathbf{3 0}\end{array}$ & $\begin{array}{c}\mathbf{3 1 -} \\
\mathbf{4 0}\end{array}$ & $\begin{array}{c}\mathbf{4 1 -} \\
\mathbf{5 0}\end{array}$ & $>\mathbf{5 0}$ \\
\hline $\begin{array}{l}\text { Instructo } \\
\text { r }\end{array}$ & 24 & 43 & 7 & 10 & 50 & - & - & 11 & 36 & 11 & 9 \\
\hline Student & 283 & 199 & 90 & 338 & 54 & 415 & 67 & - & - & - & - \\
\hline Total & 307 & 242 & 97 & 348 & 104 & 415 & 67 & 11 & 36 & 11 & 9 \\
\hline
\end{tabular}

Although the institution has a big population of students and instructors, unfortunately the actual population of the active e-learning users is unknown. Even the enrolment of the students and instructors to the system was done, however we could not ensure that they are truly familiar with the system even they claimed that they have experience with the LMS. Therefore we accept the margin of error $(E)$ to be $10 \%$, with $90 \%$ of confidence level $(\alpha=0.10)$. Based on $\mathrm{n}=0.25\left(\mathrm{Z}_{\alpha / 2} / \mathrm{E}\right)^{2}[52]$, where on $Z_{0.05}=1.64$ and $E=0.1$, the recommended size is 67 . At the end of the survey, we have obtained a total of 549 valid responses - 482 from the students and 67 from the instructors. Therefore we achieve the minimum recommended sample size. Table 1 shows the statistics of the respondents according to role, gender, experience with the LMS and age group.

\subsection{Results}

There are nine dependent variables and four independent factors in our hypotheses tests. The dependent variables are (1) CF (confusing features), (2) TM (too many features), (3) CL (consistent layout), (4) VH (visible hyperlink), (5) IL (informed location), (6) FE (features are explained), (7) CT (clear terms), (8) NV (navigation experience satisfaction) and (9) UI (user interface design satisfaction). The four independent factors are (i) user role, (ii) gender, (iii) experience and (iv) age (see Section 5.1). To test H1, we performed Pearson Correlation Test to check whether the nine dependent variables are correlated to each other, especially to the navigation satisfaction and UI satisfaction.

Table 2. Pearson Correlations table with P-values

\begin{tabular}{|c|c|c|cccccccccc|}
\hline Var. & Mean & S.D & CF & TM & CL & VH & IL & FE & CT & NV & UI \\
\hline CF & 1.68 & 0.46 & $(.754)$ & & & & & & & & \\
TM & 2.66 & 0.72 & $\mathbf{. 0 0 0}$ & $(.759)$ & & & & & & & \\
CL & 2.43 & 0.70 & .433 & .834 & $(.661)$ & & & & & & \\
VH & 2.46 & 0.70 & $\mathbf{. 0 0 1}$ & .158 & $\mathbf{. 0 0 0}$ & $(.633)$ & & & & & \\
IL & 2.69 & 0.74 & $\mathbf{. 0 0 4}$ & .861 & $\mathbf{. 0 0 0}$ & $\mathbf{. 0 0 0}$ & $(.652)$ & & & & \\
FE & 2.66 & 0.71 & $\mathbf{. 0 0 2}$ & .293 & $\mathbf{. 0 0 0}$ & $\mathbf{. 0 0 0}$ & $\mathbf{. 0 0 0}$ & $(.650)$ & & & \\
CT & 2.81 & 0.76 & $\mathbf{. 0 0 0}$ & .306 & $\mathbf{. 0 0 0}$ & $\mathbf{. 0 0 0}$ & $\mathbf{. 0 0 0}$ & $\mathbf{. 0 0 0}$ & $(.647)$ & & \\
NV & 2.76 & 0.71 & $\mathbf{. 0 0 0}$ & $\mathbf{. 0 0 0}$ & $\mathbf{. 0 0 0}$ & $\mathbf{. 0 0 0}$ & $\mathbf{. 0 0 0}$ & $\mathbf{. 0 0 0}$ & $\mathbf{. 0 0 0}$ & $(.680)$ & \\
UI & 2.71 & 0.75 & $\mathbf{. 0 0 0}$ & $\mathbf{. 0 0 1}$ & $\mathbf{. 0 0 0}$ & $\mathbf{. 0 0 0}$ & $\mathbf{. 0 0 0}$ & $\mathbf{. 0 0 0}$ & $\mathbf{. 0 0 0}$ & $\mathbf{. 0 0 0}$ & $(.635)$ \\
\hline
\end{tabular}

Cronbach's $\alpha=.725 ; N=549$

Correlation is significant at the $P<0.01$ level (2-tailed)(in bold)

Reliabilities (Cronbach's $\alpha$ if deleted) are shown in parentheses. 
Table 2 shows the Pearson correlations among the variables. Each value shows the Probability $(P)$ values associated with the significance tests (two-tailed). Each highlighted cell shows the significant correlation between two specific variables at the 0.01 level. The results show that TM is only correlated to CF, NV and UI, which indicates that if a user perceives that a page is packed with too many features, he or she may find at least a feature is confusing, hence affecting his/her satisfaction of navigation experience and user interface design. However, the perception of TM does not affect other areas such as CL. Table 2 also shows that generally CL, VH, IL, FE, CT are related to each other. CF correlates to all other variables except CL. This indicates that how the users perceive CF does not affect their perceptions of layout consistency. However, it affects their perceptions of other areas, such as their current location, terms used, explanation on the features and visibility of the features. Finally, the results prove that the users' perceptions of CF, TM, CL, VH, IL, FE and CT significantly affect their satisfaction levels of NV and UI.

To answer the hypotheses $\mathrm{H} 2$ to $\mathrm{H} 8$, we performed Univariate Analysis of Variance (ANOVA) tests. As discussed in Section 5.5, we set the margin of error to be $10 \%$, with $90 \%$ of confidence level. Due to the user age groups are varied according to role, therefore to test $\mathrm{H} 5$ we analysed the age factor in blocks, where each block consists of different role.

Table 3 shows the results for hypotheses $\mathrm{H} 2$ to $\mathrm{H} 5$. Those $P$-values $<0.10$ shown in bold indicate that the differences between the paired means exist (as the null hypothesis, $\mathrm{H}_{0}: \quad{ }_{1}={ }_{2}=\ldots$ is rejected). Role and gender are the most significant factors, which affect users' perceptions of at least four variables. Experience and age are the least significant factors as they only affect users' perceptions of two dependent variables. Experience differences affect CF and UI, and age differences affect CF and IL. Age differences do not affect NV and UI. Table 4 shows the mean values of all variables.

Table 3. Analysis of Variance for One Factor ( $P$-values), $N=549$

\begin{tabular}{|l|c|c|c|c|c|c|c|c|c|}
\hline Variables & CF & TM & CL & VH & IL & FE & CT & NV & UI \\
\hline H2: Role & $\mathbf{0 . 0 0 0}$ & 0.849 & $\mathbf{0 . 0 0 5}$ & 0.147 & 0.175 & 0.120 & $\mathbf{0 . 0 5 5}$ & 0.185 & $\mathbf{0 . 0 7}$ \\
H3: Gender & 0.331 & $\mathbf{0 . 0 6 0}$ & $\mathbf{0 . 0 1 5}$ & $\mathbf{0 . 0 1 8}$ & $\mathbf{0 . 0 4 9}$ & 0.511 & 0.728 & $\mathbf{0 . 0 0 7}$ & $\mathbf{0 . 0 8 7}$ \\
H4: Experience & $\mathbf{0 . 0 2 8}$ & 0.103 & 0.284 & 0.878 & 0.309 & 0.206 & 0.47 & 0.36 & $\mathbf{0 . 0 1 2}$ \\
H5: Age & $\mathbf{0 . 0 5 1}$ & 0.161 & 0.993 & 0.494 & $\mathbf{0 . 0 3 1}$ & 0.505 & 0.503 & 0.299 & 0.684 \\
\hline
\end{tabular}

Highlighted in bold: Interaction is significant at the $P<0.10$ level

Table 4. Comparisons of Means ( )

\begin{tabular}{|c|c|c|c|c|c|c|c|c|c|c|c|c|c|}
\hline \multirow{3}{*}{ Var. } & \multicolumn{2}{|c|}{ Role } & \multicolumn{2}{|c|}{ Gender } & \multicolumn{3}{|c|}{ Experience (year) } & \multicolumn{6}{|c|}{ Age (year) } \\
\hline & \multirow[b]{2}{*}{ Stud. } & \multirow[b]{2}{*}{ Instr. } & \multirow[b]{2}{*}{ M. } & \multirow[b]{2}{*}{ F. } & \multirow[b]{2}{*}{$<1$} & \multirow[b]{2}{*}{$1-2$} & \multirow[b]{2}{*}{$\mathbf{3}$} & \multicolumn{2}{|c|}{ Student } & \multicolumn{4}{|c|}{ Instructor } \\
\hline & & & & & & & & 17-20 & $21-25$ & $26-30$ & $31-40$ & 41-50 & $>50$ \\
\hline $\mathbf{C F}$ & 1.71 & 1.48 & 1.67 & 1.71 & 1.69 & 1.72 & 1.58 & 1.72 & 1.71 & 1.18 & 1.58 & 1.36 & 1.68 \\
\hline TM & 2.66 & 2.64 & 2.61 & 2.72 & 2.75 & 2.67 & & 2.69 & 2.4 & 2.55 & 72 & 2.36 & 2.66 \\
\hline CL & 2.46 & 2.21 & 2.50 & 2.35 & 2.47 & 2.45 & 2.34 & 2.47 & 2.46 & 2.27 & 2.17 & 2.27 & 2.43 \\
\hline VH & 2.48 & 2.34 & 2.52 & 2.38 & 2.45 & 2.45 & 2.49 & 2.47 & 2.53 & 2.45 & 2.22 & 2.64 & 2.46 \\
\hline IL & 2.67 & 2.81 & 2.75 & 2.62 & 2.61 & 2.69 & & 2.63 & 2.9 & 2. & & 3.00 & 2.69 \\
\hline FE & 2.65 & 2.79 & 2.65 & 2.69 & 2.63 & 2.64 & 2.78 & 2.64 & 2.71 & 2.61 & 2.75 & 2.85 & 2.66 \\
\hline CT & 2.79 & 2.99 & 2.81 & 2.83 & 2.75 & 2.82 & 2.88 & 2.79 & 2.81 & 2.82 & 3.00 & 2.82 & 2.82 \\
\hline NV & 2.74 & 2.87 & 2.83 & 2.67 & 2.75 & 2.73 & 2.85 & 2.73 & 2.81 & 3.18 & 2.69 & 3.09 & 2.76 \\
\hline $\mathbf{U I}$ & 2.69 & 2.87 & 2.76 & 2.65 & 2.58 & 2.70 & 2.88 & 2.67 & 2.81 & 2.91 & 2.78 & 3.00 & 2.71 \\
\hline
\end{tabular}


Since the age groups of students and instructors are different, and these two groups of users are able to see different amount of features due to different authorization level, we further investigate the differences between instructor and students. Table 5 shows the ANOVA test results, which illustrate the significant effects of the three independent variables according to role (in bold).

The results in Table 5 indicate that none of the differences among instructors' genders and age groups are significant for any of the dependent variables. Experience differences only affect FE. For students, the gender differences are most significant for all variables but FE and CT. Experience and age differences are not as significant as gender. Experience differences only affect different students' perceptions of UI, and students with different ages have different perceptions of TM and IL.

Table 5. Analysis of Variance for One Factor ( $P$-values), by Role

\begin{tabular}{|c|c|c|c|c|c|c|c|c|c|c|}
\hline \multicolumn{2}{|c|}{ Variables } & CF & TM & CL & VH & IL & FE & CT & NV & UI \\
\hline \multirow{3}{*}{$\begin{array}{l}\text { Instructor } \\
(N=67)\end{array}$} & \multirow{3}{*}{$\begin{array}{l}\text { H3: Gender } \\
\text { H4: } \\
\text { Experience } \\
\text { H5: Age }\end{array}$} & 0.788 & 0.293 & 0.396 & 0.276 & 0.584 & 0.417 & 0.408 & 0.354 & 0.564 \\
\hline & & 0.222 & 0.258 & 0.216 & 0.558 & 0.469 & 0.095 & 0.575 & 0.283 & 0.871 \\
\hline & & 0.101 & 0.623 & 0.934 & 0.274 & 0.779 & 0.496 & 0.461 & 0.192 & 0.786 \\
\hline \multirow{3}{*}{$\begin{array}{l}\text { Student } \\
(N=482)\end{array}$} & \multirow{3}{*}{$\begin{array}{l}\text { H3: Gender } \\
\text { H4: } \\
\text { Experience } \\
\text { H5: Age }\end{array}$} & 0.066 & 0.009 & 0.060 & 0.056 & 0.032 & 0.878 & 0.794 & 0.000 & 0.017 \\
\hline & & 0.209 & 0.118 & 0.982 & 0.104 & 0.219 & 0.488 & 0.497 & 0.264 & 0.017 \\
\hline & & 0.812 & 0.022 & 0.980 & 0.436 & 0.001 & 0.389 & 0.758 & 0.428 & 0.164 \\
\hline
\end{tabular}

Highlighted in bold: Interaction is significant at the $P<0.10$ level

To answer hypotheses $\mathrm{H} 6$ to $\mathrm{H} 8$, we tested the interaction effects of the independent variables. The effect of a factor is defined to be the change in response produced by a change in the level of the factor. When there is a difference in response between the levels of one factor (e.g. role has 2 levels - student and instructor) is not the same at all levels of the other factors (e.g. gender has 2 levels, male and female), then interaction between factors occur [53].To test H6, we conducted two-way between groups ANOVA analysis to test the interaction effects of three factors - role, gender and experience. Since age groups are varied according to role, to test the interaction of age with other factors, we conducted separate analyses to test $\mathrm{H} 7$ and $\mathrm{H} 8$.

Table 6 shows the results for the hypothesis H6. Item H6.1 shows that there is a significant interaction between role, gender and experience for UI. Figure A.1 and Figure A.2 in the Appendix show the means of the nine dependent variables comparing these three factors. Figure A.1 shows that the male and female instructors who have less than one year experience own different perceptions of UI. The diagram shows that female instructors are satisfied with UI while males are unsatisfied with it. Item H6.2 shows that role and gender interact with each other and provide significant effects to TM and NV. Item H6.3 shows that the interactions between role and experience exist for $\mathrm{CF}$ and FE. Item H6.4 shows that the interaction between gender and experience is the not significant at all. 
International Journal of Software Engineering \& Applications (IJSEA), Vol.4, No.5, September 2013

Table 6. Two-way ANOVA analyses for interactions between role, gender and experience ( $P$-values)

\begin{tabular}{|l|ccccccccc|}
\hline Variables & CF & TM & CL & VH & IL & FE & CT & NV & UI \\
\hline H6.1: Role * Gender * & 0.164 & 0.801 & 0.622 & 0.405 & 0.876 & 0.177 & 0.211 & 0.185 & $\mathbf{0 . 0 3 3}$ \\
Experience & & & & & & & & & \\
H6.2: Role * Gender & 0.369 & $\mathbf{0 . 0 4}$ & 0.979 & 0.771 & 0.844 & 0.465 & 0.358 & $\mathbf{0 . 0 3 2}$ & 0.168 \\
H6.3: Role * Experience & $\mathbf{0 . 0 4 6}$ & 0.264 & 0.358 & 0.190 & 0.191 & $\mathbf{0 . 0 8 2}$ & 0.374 & $\mathbf{0 . 0 9 2}$ & 0.300 \\
H6.4: Gender * Experience & 0.805 & 0.306 & 0.598 & 0.871 & 0.509 & 0.639 & 0.500 & 0.128 & 0.944 \\
\hline
\end{tabular}

Highlighted in bold: Interaction is significant at the $P<0.10$ level. $N=549$.

Table 7 shows the results for hypothesis H7. There is no significant three-factorial interaction between instructor age, gender and experience for every dependent variable. Age has not a significant effect at all for instructors. According to item H7.3, experience and gender interacts and provide significant effects to CF and TM. Figure A.8 and Figure A.9 show the relationship between instructor gender and experience. Female instructors' perceptions are quite uniform regardless their experience levels, however there are visible differences among the male instructors themselves. Male instructors with different experience levels have different perceptions of CF and TM.

Table 7.Two-way ANOVA analyses for interactions between instructor's age, gender and experience ( $P$ values)

\begin{tabular}{|l|ccccccccc|}
\hline Instructor Variables & CF & TM & CL & VH & IL & FE & CT & NV & UI \\
\hline H7.1: Age * Gender* & 0.669 & 0.616 & 0.837 & 0.468 & 0.565 & 0.984 & 0.933 & 0.773 & 0.682 \\
Experience & 0.484 & 0.599 & 0.271 & 0.445 & 0.511 & 0.636 & 0.775 & 0.305 & 0.215 \\
H7.2: Age * Experience & 0.055 & $\mathbf{0 . 0 7 4}$ & 0.399 & 0.580 & 0.590 & 0.351 & 0.966 & 0.179 & 0.423 \\
H7.3: Gender * Experience & 0.840 & 0.328 & 0.127 & 0.893 & 0.858 & 0.648 & 0.744 & 0.377 & 0.925 \\
H7.4: Gender * Age & 0.9 &
\end{tabular}

Highlighted in bold: Interaction is significant at the $P<0.10$ level. $N=67$.

Table 8 shows the results for students. According to the table, there is a significant three-factorial interaction for UI as shown in Item H8.1. This indicates that at least one group of students with certain age, gender and experience perceive UI differently compared to others. Figure A.10 and Figure A.11 in Appendix show the relationships between student experience and age according to gender. Figure A.11 shows that the female students who have more than 3 years experience perceive UI differently in between age groups. Those students who are within 17-20 years old are less satisfied with UI compared to those who are above 21 years old. As shown in Figure A.10, the least satisfied group of students are those male who are above 21 years old and have more than 3 years experience. Item H8.2 in Table 8 shows that the interaction between age and experience is not significant at all. Item H8.3 and Item H8.4 show that the gender interacts with age and experience, and their interactions are significant to TM.

Table 8: Two-way ANOVA analyses for interactions between student's age, gender and experience $(P$ values)

\begin{tabular}{|l|ccccccccc|}
\hline Student Variables & CF & TM & CL & VH & IL & FE & CT & NV & UI \\
\hline H8.1: Age * Gender* & 0.675 & 0.766 & 0.677 & 0.532 & 0.298 & 0.375 & 0.438 & 0.265 & $\mathbf{0 . 0 9 2}$ \\
Experience & 0.393 & 0.202 & 0.522 & 0.359 & 0.215 & 0.946 & 0.635 & 0.588 & 0.859 \\
H8.2: Age * Experience & 0.765 & $\mathbf{0 . 0 7 8}$ & 0.712 & 0.966 & 0.239 & 0.632 & 0.709 & 0.592 & 0.356 \\
H8.3: Gender * Experience & 0.918 & $\mathbf{0 . 0 2 1}$ & 0.973 & 0.853 & 0.137 & 0.617 & 1.000 & 0.890 & 0.31 \\
H8.4: Gender * Age & & & & & & & & & \\
\hline
\end{tabular}


International Journal of Software Engineering \& Applications (IJSEA), Vol.4, No.5, September 2013

Highlighted in bold: Interaction is significant at the $P<0.10$ level. $N=482$.

\section{DISCUSSIONS}

\subsection{Correlation}

The results from Table 1 show that all items are correlated with each other, except a few cases. First, TM is only correlated to CF, NV and UI. It indicates that when the users perceive the page is packed with too many features (TM), they may encounter some confusing features (CF), and this affects their satisfaction levels of navigation experience (NV) and UI design. However, their perceptions of TM do not affect their perceptions of other areas, such as hyperlink visibility, features explanation, inter alia. Next, CL correlates to other items but CF and TM. This suggests that the perception of page layout consistency is not affected by their views for these two areas. Overall all items are correlated to NV and UI. Hence it is proven that the users' perceptions of the seven factors as discussed in Section 5.1, do affect the user satisfaction of the navigation experience and user interface design.

\subsection{Role}

From Table 3, it is proven that instructors' perceptions are different from students' perceptions, particularly for CF, CL, CT and UI. According to Table 4, most instructors agree on CF $(=1.48)$ and have low agreement on CT ( $=2.99)$, hence leading to lower satisfaction of UI ( $=2.87)$ than students. One intriguing explanation for these results is that instructors are allowed to view more features than students, therefore the chance they encounter confusing features and ambiguous terms is higher. Despite of that, both students and instructors are having similar view on TM, which means that their acceptance levels on the number of features offered to them are similar. It shows that the user tolerance level on TM may not be directly correlated to the number of features being displayed. However, further research needs to be conducted to verify this assumption.

In a further analysis to discover the differences between instructors and students, Table 5 shows that there is almost no significant factor that affects the instructors' perceptions of all variables, except experience that affects FE. This indicates that generally almost all instructors have similar perceptions of the nine dependent variables regardless age and gender. Only those with different years of experience perceive the feature explanations differently.

For students, gender differences are very significant as the factor affects seven variables, namely CF, TM, CL, VH, IL, NV and UI. Student experience and age are less significant as experience only affects students' views of UI, while age differences are only significant for TM and IL. To conclude, it is very important to consider student demographic background while designing the LMS or creating the adaptive system for LCD, especially to design the system according to gender.

\subsection{Gender}

Gender is the most significant factor that provides main effects to TM, CL, VH, IL, NV and UI. Therefore it is proven that different genders have different preferences or requirements of the design. According to Table 4, it is visibly that female users have higher satisfaction levels of NV and UI. The female users also have more positive perceptions of TM, CL, VH and IL than males, indicates that they have more positive emotion towards the design factors. As such, we can conclude that the male users tend to feel more frustrated with these factors than females when they are given the same LMS. For other factors such as CF, FE and CT, there are almost no differences between male and female users. 
International Journal of Software Engineering \& Applications (IJSEA), Vol.4, No.5, September 2013

\subsection{Experience}

Overall, the user perceptions of CF ( >1.50), CL, VH, IL, FE, CT, NV and UI are positive ( <3.00, indicates satisfaction) regardless their levels of experience. TM is the only variable that all of them are not satisfied with ( $<3.00$, means they agree that the page is packed with too many features). [34] claimed that novice users may easily feel more frustrated than experienced users when navigating a new computer system. However the research findings show that in general experience does not affect the LMS user perceptions of all dependent variables, except CF and UI. According to Table $\backslash$ ref $\{$ table4\}, it is interesting to note that the novice users (with less than one year experience) have higher mean values for TM and $\mathrm{CF}$, and lower values for all other variables (except CL) than the most experienced users (with more than 3 years experience). This indicates that the novices are more satisfied with the LMS design than those experienced users. Therefore, this study produces different results from what was claimed by [34]. One possible explanation is when the users spend more time on the LMS, they may explore more features than those novices. Therefore, they may then discover more features they perceive frustrating.

\subsection{Age}

Except TM, generally the users are satisfied with all the variables, with only a few exceptions. First, it is proven that age differences affect users' perceptions of CF and IL. From Table 4, it is visibly that most instructors who are from $26-30$ and $41-50$ years old agree with CF $(<1.50)$. Besides, those instructors from 41-50 years old cannot judge IL $(=3.00), \mathrm{NV}(=3.09)$ and UI ( =3.00); those who are from 31-40 years old cannot judge CT ( $=3.00)$; and those who are from 26-30 years old are not satisfied with NV $(=3.18)$.

As in the exploratory research to test $\mathrm{H} 5$, those who are from 17-20 and 21-25 years old are satisfied with all the design factors, NV and UI. In the study of age impacts to instructors and students' perceptions, Table $\backslash$ ref $\{$ table5 $\}$ shows the age differences are not important for instructors but they significantly affect students' perceptions of TM and IL. Besides, the results from Table Iref \{table4\} show that those younger students (17-20 years old) have higher mean for TM and lower mean values for VH, IL, FE, CT, NV and UI, indicates that this group of users are more satisfied with the LMS design than those older students. This result is consistent with the analysis of experience, which proves that the novices are more satisfied than those experienced users. This argument is supported by the Pearson Correlation test on the student sample, which proves that the correlation between student age and experience is significant $(P=.000, N=482$ and correlation is significant at 0.01 level).

Although ageing was associated with slight slowing of performance due to slowing of cognitive [33]. However, this research could not suggest that the users' perceptions of the features that require users' cognitive processing, such as $\mathrm{CF}, \mathrm{VH}, \mathrm{IL}, \mathrm{FE}, \mathrm{CT}$ are affected by age. Our explanation is that although age may be still related to the implicit changes in higher-level processes of visual that could cause slower performance, nevertheless this does not significantly affect their tolerance levels of the design factors that cause frustration.

\subsection{Interaction between Factors}

Interaction between factors occurs when there is a difference in response between one factor levels and other factor's levels. Testing the interaction between factors that may be present is necessary to avoid misleading conclusions [53]. In our study, the results prove that there are several significant interactions among two or three factors and provide effects to at least one dependent variable. Sections below discuss the significant interactions occur in the research. 
International Journal of Software Engineering \& Applications (IJSEA), Vol.4, No.5, September 2013

\subsubsection{Interaction between Role, Gender and Experience}

There is a significant three-way interaction between role, gender and experience that affects UI. Figure A.1 shows that the mean of UI for female instructors increases level by level of experience, which indicates that UI satisfaction decreases when they gain more experience with the LMS. However male instructors show improvement on their satisfaction with the UI after they use the system for more than one year. It is also visibly that those male instructors with less than 1 year experience have lowest satisfaction levels of UI ( $=3.67)$.

On the other side, Figure A.2 shows that student UI satisfaction decreases level by level of experience (as mean value increases for all genders). However, female students are generally more satisfied with the UI design than male students across all levels of experience. Lastly, Figure A.1 and Figure A.2 clearly show that the interaction between gender and experience is in fact significant for instructors only. For students, there is no interaction between these two factors.

\subsubsection{Interaction between Age, Gender and Experience}

The three-way interaction between age, gender and experience is only significant for students but not instructors. The interaction of these three factors is important to affect the students' perceptions of UI, although the significance level is not very high $(P=0.092)$. Figure A.10 and Figure A.11 show the relationship between student age and experience according to gender. Figure A.10 shows those male students' satisfaction levels of UI become lower over experience years (as mean increases). Averagely the experienced male students (21-25 years old with more than 3 years experience) are least satisfied with the UI design ( $=3.31)$. Figure A.11 shows that female students' satisfaction level also decreases level by level of experience, except those experienced females who are within 21-25 years old and with more than 3 years experience. Unlike the male students from the same category, this group of female students is quite satisfied with the UI design ( $=2.38$ ). Generally female students are more satisfied with the UI design than male students. The most satisfied users with the UI design are those female students who are from 21-25 years old and with less than 1 year experience $(=2.33)$.

\subsubsection{Interaction between Role and Gender}

The interaction between role and gender is significant for TM and NV. Figure A.3 and Figure A.4 in the Appendix clearly show that different genders with different roles have different perceptions of TM and NV. Figure A.3 shows that female instructors are less satisfied with TM $(=2.56)$ than male instructors $(=2.79)$. In contrast to that, female students are more satisfied with TM ( $=2.76)$ if compared to male students $(=2.59)$. On the other hand, Figure A.4 shows that female instructors have the highest mean value of $\mathrm{NV}(=2.93$, lowest satisfaction) but adversely female students are the one who have lowest mean ( $=2.61$, highest satisfaction). However, there is no significant difference between male instructors' and students' perceptions of NV.

\subsubsection{Interaction between Role and Experience}

The interaction between role and experience is significant for CF, FE and NV. Figure A.5 shows that generally the users disagree with $\mathrm{CF}$ regardless their experience levels, except the instructors with less than 2 years experience. This implies that those instructors with lesser experience are easily confused with the features in the LMS. On the other hand, Figure A.6 shows that the satisfaction level of the instructors with less than 1 year experience is the lowest for FE ( $=3.14)$ amongst all users. Figure A.7 also shows that the same group of instructors are least satisfied with $\mathrm{NV}($ =3.29). Overall, students are generally satisfied with FE and NV regardless their experience levels. The reason behind the differences between students and instructors, particular for those 
who are new to the LMS, could be due to the instructors are able to access more features than the students. Therefore the chance for the instructors to discover some confusing features is higher than the students. Besides, their navigation experience is affected when they perceive that the system does not provide good explanations about the features.

\subsubsection{Interaction between Gender and Experience}

The interaction between gender and experience in overall is not significant at all. However, when examining the relationship between gender and experience according to role, there are a few main effects. First, the interaction between gender and experience affects instructors' perceptions of CF and TM. Second, the interaction between gender and experience affects students' perceptions only of TM. As instructors are able to view more features than students, it is possible that it will affect their perceptions of TM and CF. Despite that the students use lesser functionality, overall they also agree on TM $(=2.66)$. However those students with different gender and experience have different perceptions of TM.

According to Figure A.8, generally all instructors with less than 2 years experience (regardless gender) agree with CF $(<1.50)$. There are distinct perceptions between the male and female instructors who have more than 3 years experience. For the female instructors who have 3-4 years experience, they disagree with $\mathrm{CF}(=1.69)$ but males agree with that $(=1.33)$. For the instructors with more than 5 years experience, males appear to disagree with $\mathrm{CF}(=1.75)$ while females agree with that $(=1.36)$. According to Figure A.9, generally all users have similar perceptions of TM, except the male instructors with 3-4 years experience, who are the most unsatisfied users with the number of features available on a page $(=1.67)$; and most of the male users who have more than 5 years experience, could not judge their perceptions of TM $(=3.00)$.

On the other hand, according to Figure A.12, the main difference exists between male students with more than 3 years experience and the others. The mean value of TM for those experienced male students is the lowest among all students, indicates that they agree the most that the page is packed with too many features $(=2.24)$. Therefore it is proven that there is a significant difference between genders among students, particularly on the perceptions of TM.

\subsubsection{Interaction between Age and Gender}

We tested the interaction between gender and age according to role as the age groups of each role are mutually exclusive from each other. The findings show that the interaction of these two factors is not significant at all for instructors. However, there is a significant effect for students. The interaction between gender and age affects students' perceptions of TM. From Figure A.13, it is visibly that female students are generally more satisfied with the number of features displayed, while male students are less satisfied. Male students who are above 21 years old agree the most that the page is packed with too many features $(=2.30)$. In contrast, the females who are in the same age group have lowest agreement with that $(=2.86)$. As student age is proven correlated to student experience, this result is consistent with the findings for interaction between gender and experience above. In other words, the students who are above 21 years old usually have more than 3 years experience. Although we agree that experience causes the change of perceptions of TM (as discussed in Section 6.4), nevertheless this argument does not fit in with experienced female users. The factor that causes the main difference between two genders is in fact unknown. Further research should be conducted to investigate the main factors that cause such different perceptions among students with different genders and age groups.

\subsubsection{Interaction between Age and Experience}

The interaction between age and experience is not significant at all for both instructors and students. Although student age is correlated to student experience, but there is no interaction 
between these two factors. Besides, age is not correlated to experience for instructors. In conclusion, the main effects of age and experience on the dependent variables as discussed in Section 6.4 and Section 6.5 are independent from each other.

\subsection{Limitations of the Research}

Although the research managed to propose a variety of factors influencing LMS user satisfaction of navigation experience and user interface design, however it is not without limitations. First, the study gathered data from only one institution in Malaysia, limits the generality of the results. Secondly, although the sample size of the instructor fulfils the minimum requirement, however it may not significantly represent the actual population of instructors of the institution as the number is small. Thirdly we did not get equal sample size for every level of each factor in the ANOVA test, which can affect the homogeneity of variance assumption. Fourth, we did not assess how frequent the users use the LMS to indicate how active or how familiar they are with the system. Therefore we could not estimate the actual population of the active e-learning users. Lastly, although the courseware and specific class are pre-structured by the system administrators, and there is a default design that is shared by all users in general. However, the information and the number of courses (or features) the users can view is not exactly the same. Therefore, there might be some biases in the results. Acknowledging these limitations, it is important to conduct experiment in the future to ensure they are exposed to the identical environment. The results should also be improved by carrying out additional research to capture how role, gender, age and experience differ in their actual usage of the LMS.

\section{SUMMARY}

The implications of this study are noteworthy for academics and practitioners alike. Results indicate a genuine socio-demographic effect in some aspects in LMS design. From an academic researcher's perspective, the findings suggest that user interface design and development should attempt to account for role, gender, experience and age effects when testing for the usability of the LMS. From a practitioner point of view, it is important for the LMS developers and designers to consider their users from different socio-demographic background, and to understand that different users have different perceptions and requirements of the design. This study provides insights for LMS developers to strengthen their LMS design and further improve user satisfaction, not only for learners but instructors as well. An unsatisfactory will hamper users' motivation to continue using the LMS as a platform for teaching and learning.

Seven factors that may cause frustrations to e-learning users are studied, namely CF, TM, CL, VH, IL, FE, and CT. These factors are proven correlated to navigation experience satisfaction $(\mathrm{NV})$ and user interface design satisfaction (UI). The study also proves that not everyone has the same perception of the seven factors that cause frustrations in the LMS, and not everyone has the same level of satisfaction although they use the same system. The variations between roles, genders, experiences and ages are proven exist and should not be ignored. Roles and genders are the most significant factors in overall, and although experience and age are least significant, they should not be ignored too. The results also show that gender and age do not affect instructors' perceptions at all. Gender is the most significant factor that affects students' perceptions of almost all variables. Table 9 summarizes the results of all hypotheses testing. 
Table 9: Summary of the Results

\begin{tabular}{|c|c|c|}
\hline $\begin{array}{l}\mathbf{N} \\
\mathbf{0}\end{array}$ & Hypothesis & Significant \\
\hline 1 & Correlations of the nine dependent variables are significant & Yes \\
\hline 2 & $\begin{array}{l}\text { Different roles perceive the nine dependent variables } \\
\text { differently }\end{array}$ & Yes - CF, CL, CT, UI \\
\hline 3 & $\begin{array}{l}\text { Different gender perceive the nine dependent variables } \\
\text { differently }\end{array}$ & $\begin{array}{l}\text { Yes - TM, CL, VH, IL, NV, } \\
\text { UI; No for instructors }\end{array}$ \\
\hline 4 & $\begin{array}{l}\text { Users from different age groups perceive the nine dependent } \\
\text { variables differently }\end{array}$ & $\begin{array}{l}\text { Yes - CF, IL; } \\
\text { No for instructors }\end{array}$ \\
\hline 5 & $\begin{array}{l}\text { Users from different experience levels perceive the nine } \\
\text { dependent variables differently }\end{array}$ & Yes - CF, UI \\
\hline 6 & Interactions between role, gender and experience exist & Yes \\
\hline 7 & $\begin{array}{l}\text { Interactions between instructor's gender, experience and age } \\
\text { exist }\end{array}$ & $\begin{array}{l}\text { No; But interactions between } \\
\text { gender and experience exist }\end{array}$ \\
\hline 8 & $\begin{array}{l}\text { Interactions between student's gender, experience and age } \\
\text { exist }\end{array}$ & $\begin{array}{l}\text { Yes - except age and } \\
\text { experience }\end{array}$ \\
\hline
\end{tabular}

From the research, there are a few interesting findings that worth future research:

1. In all ANOVA tests that examine students' perceptions, none of the mean values of all dependent variables are greater than 3.00. It indicates that the student perceptions or satisfaction of the variables are positive. However, there are many areas in the instructors' perception analyses achieve mean values of at least 3.00 (c.f. Table 4). It indicates that their emotions on these areas are either neutral or towards negative. Although the reason could be due to the number of features the instructors can access is more than the students, but the actual factors that cause such differences between these two roles should be further investigated.

2. Although we agree that experience causes the change of perceptions of TM (as discussed in Section 6.4), nevertheless this argument does not fit in with experienced female users. The factor that causes the main difference between two genders is in fact unknown. Further research should be conducted to investigate the main factors that cause such different perceptions among students with different genders.

3. Table 4 shows that all users somewhat agree with TM regardless any group $(<3.00)$. Although the instructors are able to access more features than the students, nevertheless this research does not prove that instructors feel more frustrated than the students, nor the students feel more satisfied with TM than the instructors. This show that the perception of TM is not directly correlated to the number of features the LMS offers to the users. Instead, this can be related to the number of features are packed in a page, and how the information is laid.

4. [34] claimed that novice users may easily feel more frustrated than the experienced users. This research proves otherwise, where novice users are more satisfied with almost all variables than those most experienced users. One possible explanation is when the users spend more time on the LMS, they may explore more features than those novices. Therefore, they may then discover more features they perceive frustrating.

5. Although ageing was associated with slight slowing of performance due to slowing of cognitive processing speed, but that does not mean ageing is correlated to user satisfaction or perceptions of the design factors. This research shows that the variations between age groups are high. In many cases, those users who are more than 50 years old are more satisfied than those younger users.

6. When testing the interaction between two factors, there are cases where instructors and students with same gender have contradict perceptions. For instance, the experienced male instructors (with more than 3 years experience) are satisfied with the TM but students from 
the same group are not. The factors that cause such difference between role and gender should be investigated further.

As conclusion, socio-demographic factors such as role, gender, experience and age, and the interactions between these factors are proven significant, which they affect how the users perceive the LMS design of whether or not it causes frustrations. In other words, even the users are provided with the same LMS, not everyone will perceive the features as confusing, the page is packed with too many features, the layout is inconsistent, the hyperlinks are not visible, their current locations are not well-informed, the features are not well-explained, and the terms used are ambiguous. In addition, not everyone has the same satisfaction level of navigation experience and interface design.

\section{REFERENCES}

[1] M. A. Embi, "E-learning in malaysian higher education institutions: Status, trends, \& challenges," 2011.

[2] R. M. R. Hussain, "E-learning in Higher Education Institutions in Malaysia," E-mentor, vol. 5, no. 7, pp. 72-75, 2004.

[3] H. M. Selim, "Critical success factors for e-learning acceptance: Confirmatory factor models," Computers and Education, 2005.

[4] M. Masrom, O. Zainon, and R. Rahiman, "Critical success in e-learning: An examination of technological and institutional support factors," International Journal of Cyber Society and Education Pages, 2008.

[5] C. L. Goi and P. Y. Ng, "E-learning in Malaysia: Success factors in implementing e-learning program," International Journal of Teaching and Learning in Higher Education, vol. 20, no. 2, pp. 237-246, 2009.

[6] M. F. Costabile, M. De Marsico, R. Lanzilotti, V. L. Plantamura, and T. Roselli, "On the Usability Evaluation of E-Learning Applications," in Hawaii International Conference on System Sciences, 2005, vol. 1, pp. 1-10.

[7] C. Abras, D. Maloney-Krichmar, and J. Preece, "User-centered design,” Bainbridge, W.Encyclopedia of Human-Computer Interaction.Thousand Oaks: Sage Publications, vol. 37, no. 4, pp. 445-456, 2004.

[8] L. Damodaran, "User involvement in the systems design process-a practical guide for users," Behaviour \& information technology, vol. 15, no. 6, pp. 363-377, 1996.

[9] F. Klett and P. Pharow, "How to Achieve User Satisfaction in Complex E-Learning Environments," in Information Technology Based Higher Education and Training, 2006. ITHET '06. 7th International Conference on, 2006, pp. 773-785.

[10] P. Zaharias and A. Poylymenakou, "Developing a Usability Evaluation Method for e-Learning Applications : Beyond Functional Usability,' International Journal of Human-Computer Interaction, vol. 25, no. 1, pp. 75-98, 2009.

[11] D. Dhar and P. Yammiyavar, "Design Approach for E-learning Systems: Should it be User Centered or Learner Centered," in Technology for Education (T4E), 2012 IEEE Fourth International Conference on, 2012, pp. 239-240.

[12] T. Carey, K. Harrigan, A. Palmer, and J. Swallow, "Scaling up a learning technology strategy: supporting student/faculty teams in learner-centred design," Research in Learning Technology, vol. 7, no. 2, pp. 15-26, 1999.

[13] B. Han, X.-W. Hao, and C.-F. Liu, "The design and implementation of user behavior mining in Elearning system," in Automatic Control and Artificial Intelligence (ACAI 2012), International Conference on, 2012, pp. 2078-2081.

[14] G. Savic and Z. Konjovic , "Learning style based personalization of SCORM e-learning courses," in Intelligent Systems and Informatics, 2009. SISY '09. 7th International Symposium on, 2009, pp. 349-353.

[15] T. Swinke, "A unique, culture-aware, personalized learning environment," in Interactive Collaborative Learning (ICL), 2012 15th International Conference on, 2012, pp. 1-7. 
[16] R. Zhou and K. Rechert, "Personalization for Location-Based E-Learning," in Next Generation Mobile Applications, Services and Technologies, 2008. NGMAST '08. The Second International Conference on, 2008, pp. 247-253.

[17] A. Al--Dujaily and H. Ryu, "A Study on Personality in Designing Adaptive e-Learning Systems," in Eighth IEEE International Conference onAdvanced Learning Technologies, 2008. ICALT '08., 2008, pp. 136-138.

[18] E. Soloway, M. Guzdial, and K. E. Hay, "Learner-centered design: The challenge for HCI in the 21st century," interactions, vol. 1, no. 2, pp. 36-48, 1994.

[19] Q. Gu and T. Sumner, "Support Personalization in Distributed E-Learning Systems through Learner Modeling," in Information and Communication Technologies, 2006. ICTTA '06. 2nd, 2006, vol. 1, pp. 610-615.

[20] P. Q. Dung and A. M. Florea, “An Architecture and a Domain Ontology for Personalized Multi-agent e-Learning Systems," in Knowledge and Systems Engineering (KSE), 2011 Third International Conference on, 2011, pp. 181-185.

[21] M. V Judy, U. Krishnakumar, and A. G. H. Narayanan, "Constructing a personalized e-learning system for students with autism based on soft semantic web technologies," in Technology Enhanced Education (ICTEE), 2012 IEEE International Conference on, 2012, pp. 1-5.

[22] M. K. Khribi, M. Jemni, and O. Nasraoui, "Automatic Recommendations for E-Learning Personalization Based on Web Usage Mining Techniques and Information Retrieval," in Advanced Learning Technologies, 2008. ICALT '08. Eighth IEEE International Conference on, 2008, pp. 241245.

[23] N. Pandey, S. Sahu, R. K. Tyagi, and A. Dwivedi, "Learning algorithms For intelligent agents based e-learning system," in Advance Computing Conference (IACC), 2013 IEEE 3rd International, 2013, pp. 1034-1039.

[24] L. Zhuhadar, E. Romero, and R. Wyatt, "The Effectiveness of Personalization in Delivering Elearning Classes," in Advances in Computer-Human Interactions, 2009. ACHI '09. Second International Conferences on, 2009, pp. 130-135.

[25] P.-C. Sun, R. J. Tsai, G. Finger, Y.-Y. Chen, and D. Yeh, "What drives a successful e-Learning? An empirical investigation of the critical factors influencing learner satisfaction," Computers \& Education, vol. 50, no. 4, pp. 1183-1202, 2008.

[26] M. P. Penna, V. Stara, and M. De Rose, "The failure of e-learning: why should we use a learner centred design," Journal of e-Learning and Knowledge Society, vol. 3, no. 2, 2009.

[27] N. Avouris, N. Tselios, C. Fidas, and E. Papachristos, "Website evaluation: A usability-based perspective," in Advances in Informatics, Springer, 2003, pp. 217-231.

[28] J. Tidwell, Designing Interfaces, 2nd ed. Sebastopol: O’Reilly Media, 2011.

[29] A. Edmundson, Globalized e-learning cultural challenges. IGI Global, 2007.

[30] S. Downey, R. M. Wentling, T. Wentling, and A. Wadsworth, "The relationship between national culture and the usability of an e-learning system," Human Resource Development International, vol. 8, no. 1, pp. 47-64, 2005.

[31] P. Lea, "Understanding the culture of e-learning," Industrial and Commercial Training, vol. 35, no. 5, pp. 217-219, 2003.

[32] D. Gefen and D. W. Straub, "Gender differences in the perception and use of e-mail: An extension to the technology acceptance model," MIS quarterly, vol. 21, no. 4, pp. 389-400, Dec. 1997.

[33] T. Lindberg, R. Näsänen, and K. Müller, "How age affects the speed of perception of computer icons," Displays, vol. 27, no. 4๑5, pp. 170-177, 2006.

[34] J. Lazar, K. Bessiere, I. Ceaparu, J. Robinson, and B. Shneiderman, "Help! I'm Lost: User Frustration in Web Navigation,” Web Navigation, vol. 1, no. 3, pp. 18-26, 2003.

[35] N. Bevan, "Encyclopaedia of Human Computer Interaction," in Encyclopedia of human computer interaction, C. Ghaoui, Ed. Idea Group Inc (IGI), 2006, pp. 362-372.

[36] L. L. Lohr, "Designing the instructional interface," in Computers in Human Behavior, 2000, vol. 16, pp. 161-182.

[37] C. Bee and R. Madrigal, "Outcomes are in the eye of the beholder: The influence of affective dispositions on disconfirmation emotions, outcome satisfaction, and enjoyment," Journal of Media Psychology: Theories, Methods, and Applications, vol. 24, no. 4, pp. 143-153, 2012. 
[38] U. R. Hülsheger, H. J. E. M. Alberts, A. Feinholdt, and J. W. B. Lang, "Benefits of Mindfulness at Work: The Role of Mindfulness in Emotion Regulation, Emotional Exhaustion, and Job Satisfaction," Journal of Applied Psychology, vol. 98, no. 2, pp. 310-325, Mar. 2012.

[39] T. Browne, R. Hewitt, M. Jenkins, and R. Walker, "2008 survey of Technology Enhanced Learning For Higher Education in the UK.” pp. 1-58, 2008.

[40] S. Murugesan, "Web application development: Challenges and the role of web engineering," in Web engineering: modelling and implementing web applications, G. Rossi, Ed. Springer, 2008, pp. 7-32.

[41] S. E. Lakhan and K. Jhunjhunwala, "Open Source Software in Education," EDUCAUSE Quarterly Magazine, vol. 31, no. 2, pp. 32-40, 2008.

[42] B. Shneiderman, C. Plaisant, M. Cohen, and S. Jacobs, Designing the User Interface: Strategies for Effective Human Computer Interaction, 5th ed. Boston, MA: Addison-Wesley, 2005.

[43] M. Jenkins, T. Browne, and R. Walker, "A longitudinal perspective between March 2001, March 2003 and March 2005 for higher education in the United Kingdom,” 2005.

[44] Y. Guo, D. Qian, J. Guan, and J. Wang, "Usability testing on a government training platform: A case study," in 2010 2nd International Conference onEducation Technology and Computer (ICETC), 2010, vol. 2, pp. 2-214.

[45] A. Granic and V. Glavinic, "Evaluation of interaction design in web-based intelligent tutoring systems," in 28th International Conference on Information Technology Interfaces, 2006.

[46] B. L. Capehart and T. Middelkoop, Handbook of Web Based Energy Information and Control Systems. Fairmont Pr, 2011.

[47] J. Nielsen, “Top 10 Mistakes in Web Design,” vol. 2011, no. August. 2011.

[48] L. Triacca, D. Bolchini, L. Botturi, and A. Inversini, "MiLE: Systematic Usability Evaluation for Elearning Web Applications," Association for the Advancement of Computing in Education, vol. 12, no. 4, 2004.

[49] M. Levene, An Introduction to Search Engines and Web Navigation, 2nd ed. John Wiley \& Sons, 2010.

[50] P. Bradford, M. Porciello, N. Balkon, and D. Backus, "The blackboard learning system: the be all and end all in educational instruction?," Journal of Educational Technology Systems, vol. 35, no. 3, pp. 301-314, 2007.

[51] S. J. Coopman, “A critical examination of Blackboard's e-learning environment," First Monday, vol. 14, no. 6-1 June 2009, 2009.

[52] N. A. Weiss, Elementary Statistics, 6th ed. Addison-Wesley, 2004.

[53] D. C. Montgomery, Design and Analysis of Experiments. John Wiley \& Sons Singapore, 2013.

\section{APPENDIX}

\section{H6.1 Interaction between Role, Gender and Experience}

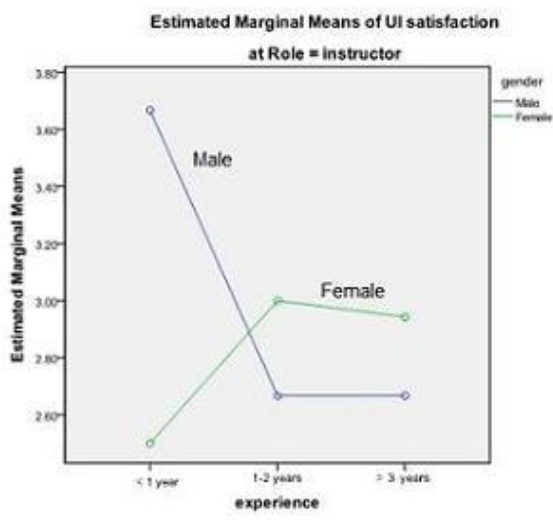

Figure A.1. Instructor Means of UI

H6.2 Interaction between Role and Gender

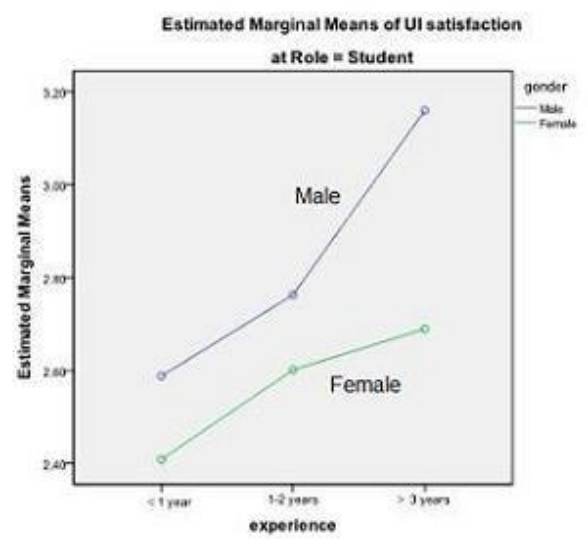

Figure A.2.Student Means of UI 
International Journal of Software Engineering \& Applications (IJSEA), Vol.4, No.5, September 2013

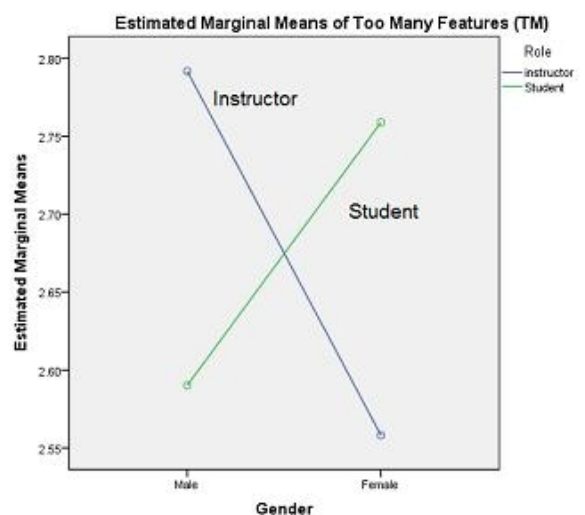

Figure A.3. Means distribution of TM

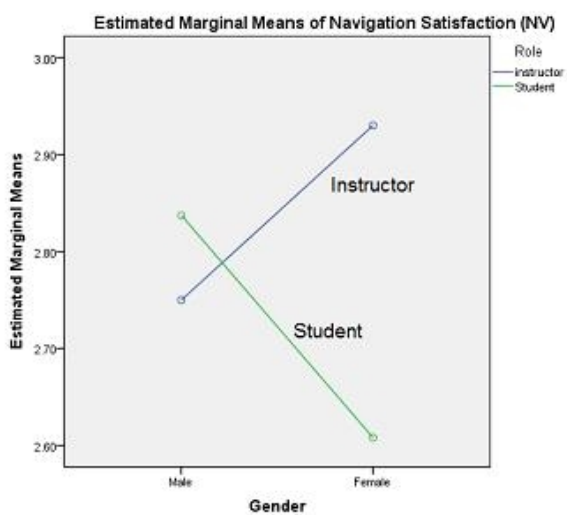

Figure A.4.Means distribution of NV

\section{H6.3 Interaction between Role and Experience}

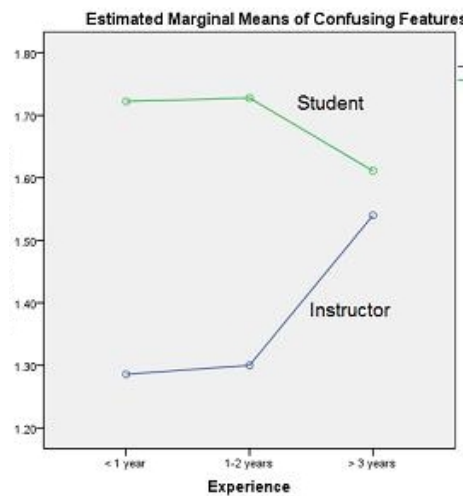

Figure A.5.

Means distribution of $\mathrm{CF}$

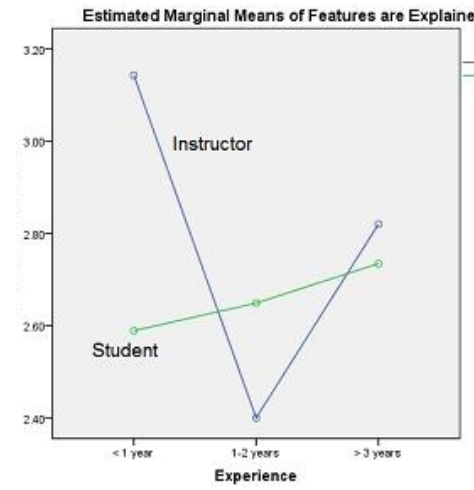

Figure A.6.

Means distribution of FE

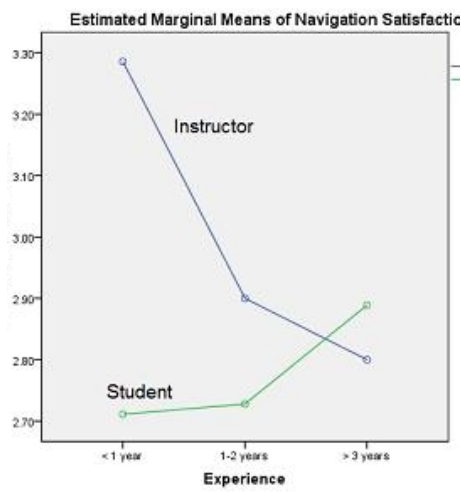

Figure A.7.

Means distribution of NV

H7.3 Interaction between Instructor Gender and Experience 
International Journal of Software Engineering \& Applications (IJSEA), Vol.4, No.5, September 2013

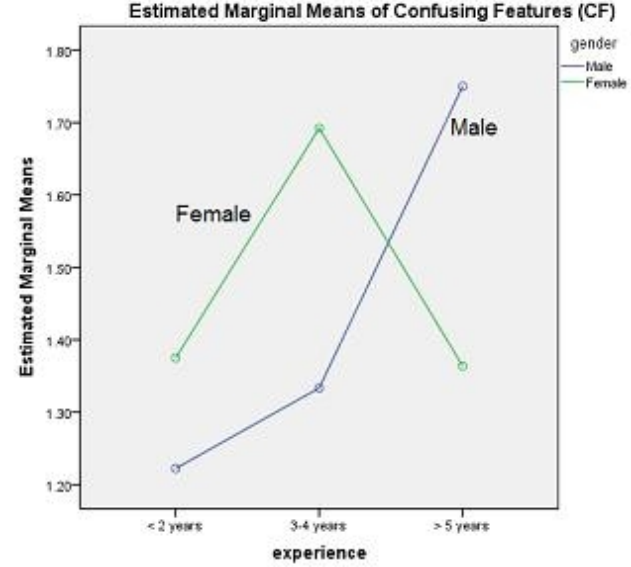

Figure A.8. Means distribution of $\mathrm{CF}$

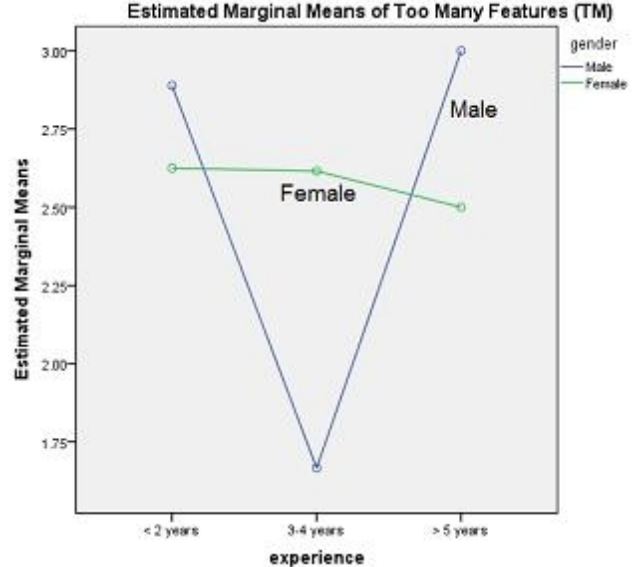

Figure A.9. Means distribution of TM

H8.1: Interaction between Student Gender, Age and Experience

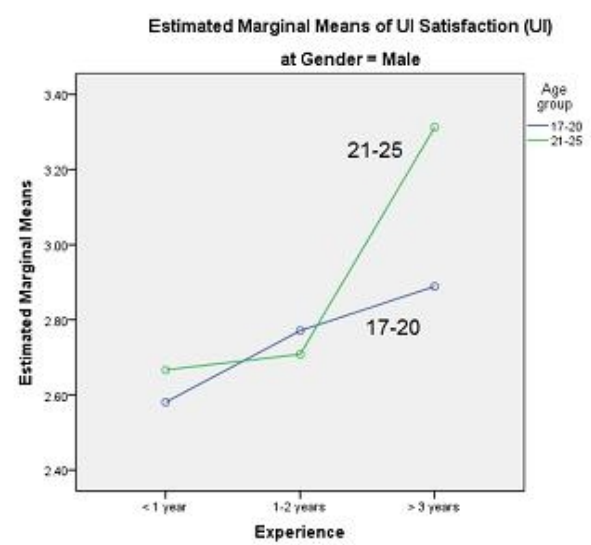

Figure A.10. Means distribution of UI (Male)

H8.3: Interaction between Student Gender and Experience

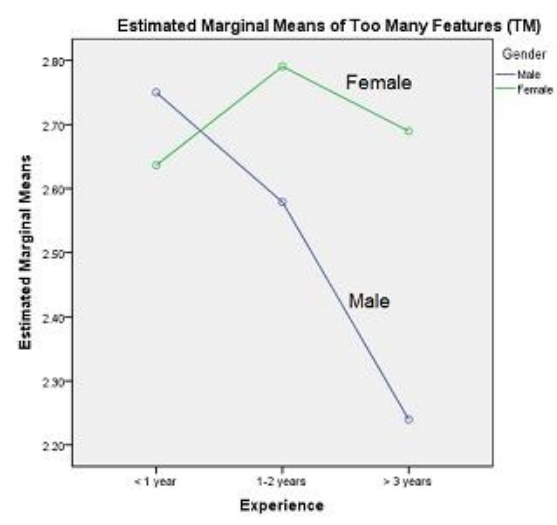

Figure A.12. Means distribution of TM

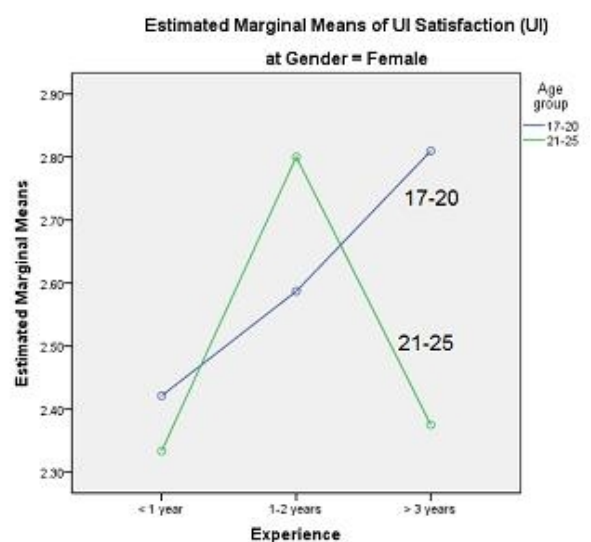

Figure A.11. Means distribution of UI (Female)

H8.4: Interaction between Student Gender and Age

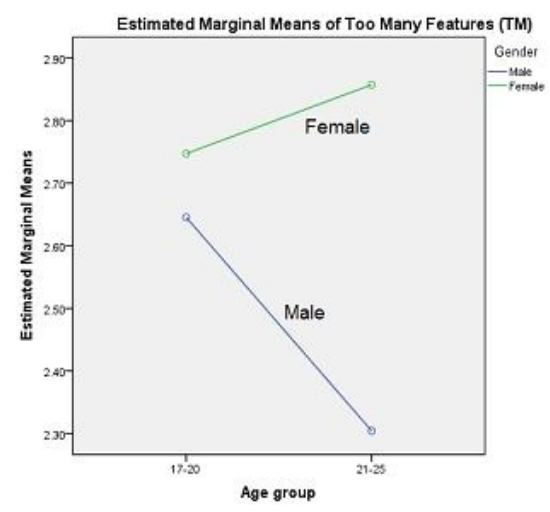

Figure A.13. Means distribution of TM 